\title{
Production of enantiopure $(R)$ - or (S)-2-hydroxy-4-(methylthio)butanoic acid by multi-enzyme cascades
}

\author{
Can Zhang ${ }^{1,2,3}$, Wei Song ${ }^{1,2,3}$, Jia Liu ${ }^{1,2,3}$, Xiulai Chen ${ }^{1,2,3}$ and Liming Liu ${ }^{1,2,3^{*}}$
}

\begin{abstract}
(R)- or (S)-2-Hydroxy-4-(methylthio)butanoic acid (HMTBA) is used as a poultry nutritional supplement and to treat renal failure disease. Herein, we report an artificially designed biocatalytic cascade process, which uses L-methionine to synthesize (R)- or (S)-HMTBA. This biocatalysis cascade comprises a basic module and two different extender modules and operates in a modular assembly manner. The basic module responsible for the transformation of L-methionine to a-keto- $\gamma$-methylthiobutyric acid (KMTB) is comprised of the L-amino acid deaminase. Two different extender modules responsible for the transformation of KMTB to (R)- or (S)-HMTBA are comprised of the R/S-specific lactate dehydrogenase in combination with the formate dehydrogenase, respectively. Engineered Escherichia coli catalysts, one containing the basic module, the other containing the one of two different extender modules, produced $97.6 \mathrm{~g} \mathrm{~L}^{-1}(R)$-HMTBA and $96.4 \mathrm{~g} \mathrm{~L}^{-1}(S)$-HMTBA with a yield of $96.9 \%$ and $95.8 \%$ at the large scale $(1 \mathrm{~L})$ using a two-stage strategy in one pot, respectively. Therefore, this biocatalytic process lays the foundation for the industrialscale conversion of low-cost L-amino acids to corresponding high-value enantiopure chiral 2-hydroxy acids.
\end{abstract}

Keywords: (R)- or (S)-2-Hydroxy-4-(methylthio)butanoic acid, Enzyme cascades, L-Amino acid deaminase, Lactate dehydrogenase, Modular assembly

\section{Introduction}

2-Hydroxy acids, which bear a hydroxyl group at the alpha site related to a carboxylic group such as phenyllactic acid, 4-hydroxyphenyl lactic acid (Busto et al. 2014) and mandelic acid (Xue et al. 2016), are commonly applied in feeds, antiseptic agents, and pharmaceuticals (Song et al. 2016; Yao et al. 2016). One of the most commercially important 2-hydroxy acids is 2-hydroxy-4(methylthio)butanoic acid (HMTBA) (Busto et al. 2014), which is a pro-drug of compound $\alpha$-keto acid tablets, as it is highly more stable and shows beneficial properties in treating renal failure disease (Masud et al. 1994). In addition, as a methionine precursor, HMTBA is widely used as a poultry nutritional supplement since it is available in liquid form and has specific nutritional (Martin-Venegas

\footnotetext{
*Correspondence: mingll@jiangnan.edu.cn

${ }^{1}$ State Key Laboratory of Food Science and Technology, Jiangnan

University, 1800 Lihu Road, Wuxi 214122, China

Full list of author information is available at the end of the article
}

et al. 2013; Tang et al. 2011) and anti-microbial properties (Dibner and Buttin 2002). Thus, to meet the increasing market demand, a practical method for the preparation of HMTBA is required.

There are two main methods currently used to produce HMTBA: chemical and enzyme methods. There are several approaches for the chemical de novo synthesis of HMTBA, including hydrolysis (e.g., with cyanohydrin and ester) (Matsuoka 1993; Ruest et al. 1985; Tsuyoshi and Masahiro 2006) and oxidation (e.g., with butadiene and ketoalcohol) (Hagiya 2008; Koji and Hiroyuki 2009). Currently, the cyanohydrin hydrolysis process (Tsuyoshi and Masahiro 2006) is the most notable commercial method for HMTBA production, using acrolein and methanethiol as the raw materials in the presence of an organic amine salt to form 3-methylthio propanal, which then reacts with hydrocyanic acid to produce 2-hydroxy4-(methylthio)butanenitrile (HMTBN), followed by hydrolysis of sulfuric acid to HMTBA. However, there 
are several drawbacks associated with this process, such as the high energy requirement given the need for high temperature and pressure in the final step (hydrolysis of HMTBN by sulfuric acid to HMTBA), potential environmental hazards, and the use of toxic acrolein, methanethiol, and hydrocyanic acid as materials.

Alternatively, biocatalytic production processes offer several advantages such as a reaction operation under milder conditions (i.e., ambient temperature and pressure), and the use of fewer and less toxic chemicals (Luo and Lee 2017). There are two reported biotransformation-based methods for producing HMTBA, involving a petroleum-derived raw substrate (HMTBN) or a biomass-derived substrate (L-methionine; L-Met). The first biocatalytic process developed for HMTBA involved nitrilase or nitrile hydratase. Nitrilase was used to directly hydrolyze HMTBN to HMTBA (Olivier et al. 2001; Jin et al. 2016), whereas HMTBN was hydrated by nitrile hydratase to 2-hydroxy-4-(methylthio)butanamide (HMTBAm), followed by a chemical or amidase reaction to transform HMTBAm to HMTBA (D et al. 2000). Despite the good yields obtained with this method, it requires HMTBN as an indispensable starting material that is spontaneously decomposed into 3-(methylthio)propionaldehyde and toxic hydrocyanic acid. Alternatively, HMTBA can be synthesized from LMet via two transformation steps: (i) L-Met to $\alpha$-keto$\gamma$-methylthiobutyric acid (KMTB), and (ii) KMTB to HMTBA. The first step involves the work of four enzymes: $\mathrm{L}$-amino acid oxidase ( $\mathrm{L}$-AAO), $\mathrm{L}$-amino acid deaminase (L-AAD), $\alpha$-amino acid aminotransferase, and L-amino acid dehydrogenase (Molla et al. 2017; Xue et al. 2018). Considering the irreversible nature of the reactions, L-AAO and L-AAD are prioritized. More recently, L-AAD from Proteus vulgaris was used for the bioconversion of $\mathrm{L}$-Met to KMTB. The engineered strain $P \nu_{\mathrm{L}}-$ $\mathrm{AAD}^{\mathrm{K} 104 \mathrm{R} / \mathrm{A} 337 \mathrm{~S}}$ produced $63.6 \mathrm{~g} \mathrm{~L}^{-1}$ of KMTB in $24 \mathrm{~h}$ with a conversion rate of $91.4 \%$ (Hossain et al. 2014); however, there are no reports on the second step alone.

In addition, Busto et al. (2014) combined the two transformations steps using a multi-enzyme cascade with LAAD from Proteus myxofaciens and D- or L-isocaproate reductases from Lactobacillus paracasei DSM 20008 or Lactobacillus confuses DSM 201966 coupled with formate dehydrogenase (FDH)-mediated NADH regeneration to produce $(R)$ - or $(S)$-HMTBA, respectively. In simultaneous mode in one pot, $30 \mathrm{~g} \mathrm{~L}^{-1}(R)$ - or $(S)$ HMTBA was obtained at the milligram scale with a conversion rate of $99.0 \%$ from L-Met after $14 \mathrm{~h}$.

However, this type of transformation at a larger scale suitable for industrial application has not yet been developed. Here, we report an artificially designed biocatalysis cascade protocol that could transform L-Met to KMTB, followed by transformation to $(R)$ - or $(S)$-HMTBA. The platform was designed as a modular assembly, enabling the tunable and predictable operation of the biocatalysis cascade. The modular assembly involving the basic module and the extender module has been applied to transformation of simple achiral glycine and aldehydes to synthesize stereodefined $\alpha$-functionalized organic acids (Song et al. 2018). This method was suitable for application as a high-yield, high-productivity platform for scaled-up HMTBA biosynthesis in a 1-L biocatalytic reaction system.

\section{Methods}

Strains, media, plasmids, reagents, and culture conditions Commercial reagents, standards, and solvents were purchased from Sigma-Aldrich, Meryer Chemicals, Aladdin, and TCI chemicals, and used without further purification. The expression plasmid pET-28a $(+)$ and the host strain E. coli BL21 (DE3) were purchased from Novagen (Madison, WI, USA). The Bacillus coagulans and Pediococcus acidilactici were conserved in China General Microbiological Culture Collection Center (CGMCC), with preservation CGMCC No.: 1.2407 and No.: 1.2696, respectively. Cultivation for gene manipulation and plasmid construction was performed in Luria-Bertani broth or agar plates $(2 \%$ agar, w/v). Cultivation for E. coli cell and enzyme expression for recombinant were performed in the Terrific Broth medium with $50 \mathrm{mg} \mathrm{L}^{-1}$ kanamycin.

\section{Construction of the strains}

All genetic constructions were carried out using standard molecular biology techniques with LATaq and rTaq DNA polymerase, restriction enzymes and T4 DNA ligase (all from Takara, Japan). Cloning inserts were created via PCR of ORFs of interest from their respective genomic or codon-optimized DNA with Phusion polymerase. Heterologous genes were amplified from their respective genomic DNA except for $P \nu \mathrm{L}$-AAD (GenBank Accession No. MK258171) and CbFDH (GenBank Accession No. MK258172), which were synthesized by GenScript (Piscataway, NJ) with codon optimization. Genes of R-specific lactate dehydrogenase (D-LDH) (KEGG: A4V11_01320) and S-specific lactate dehydrogenase (L-LDH) (KEGG: Bcoa_0653) were amplified from the genome of Pediococcus acidilactici and Bacillus coagulans, respectively. Main primers used for constructing co-expressed strains are summarized in Additional file 1: Table S1. Candida boidinii FDH was first inserted into the pET28a(+) using the restriction sites BamHI and SalI, followed with an insertion of Pediococcus acidilactici D-LDH gene and Bacillus coagulans L-LDH gene using the SalI and XhoI site, respectively. 


\section{Analytical methods}

L-Met levels were determined by HPLC using a FLD detector with an Agilent Zorbax SB-Aq column $(4.6 \times 150 \mathrm{~mm})$. HPLC analysis of L-Met was performed by automatic precolumn derivatization with $o$-phthalaldehyde (OPA). Fluorescent derivatives were detected by excitation at $330 \mathrm{~nm}$ and emission at $465 \mathrm{~nm}$. Samples $(8 \mu \mathrm{L})$ were mixed with $4 \mu \mathrm{L}$ of OPA derivatization reagent $(30 \mathrm{mg}$ OPA in $1 \mathrm{~mL}$ methanol, $53 \mu \mathrm{L} \mathrm{ME}$ and $9 \mathrm{~mL} 0.5 \mathrm{M}$ potassium borate buffer, $\mathrm{pH}$ 9.2) and stored at $-20{ }^{\circ} \mathrm{C}$ for no more than 7 days before use. The polar eluent was $10 \mathrm{mM} \mathrm{KH_{2 }} \mathrm{PO}_{4} \mathrm{pH} 5.3$ (buffer A), and the nonpolar eluent was a 5:3:1 (v/v/v) mixture of acetonitrile, methanol and $10 \mathrm{mM} \mathrm{KH}_{2} \mathrm{PO}_{4}$ (buffer B). The gradient was applied as follows: $0 \min 80 \% \mathrm{~A}, 4 \mathrm{~min} 73 \% \mathrm{~A}$, $8 \min 50 \%$ A, $12 \min 30 \%$ A, $16 \min 25 \%$ A, $20 \min 20 \%$ A, $24 \min 40 \%$ A, $28 \min 60 \%$ A, 32 min $80 \%$ A. A flow

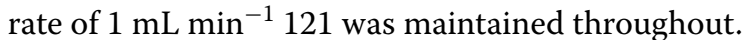

Quantitation of KMTB and HMTBA was performed by reverse-phase high-performance liquid chromatography (HPLC) using an Aminex ${ }^{\circledR}$ HPX-87H ion $(300 \mathrm{~mm} \times 250 \mathrm{~mm})$ exclusion column with $\mathrm{UV}$ detector at $210 \mathrm{~nm}$. The mobile phase was a $5 \mathrm{mM} \mathrm{H}_{2} \mathrm{SO}_{4}$ solution at a flow rate of $0.6 \mathrm{~mL} / \mathrm{min}$ and a column temperature of $35^{\circ} \mathrm{C}$. The injection volume was $10 \mu \mathrm{L}$.

Analysis of the e.e. of HMTBA was conducted using Agilent 1260 HPLC with Daicel CHIRALPAK IG-3 column $(250 \times 4.6 \mathrm{~mm}, 3 \mu \mathrm{m}$; Daicel Co., Japan $)$ with UV detector at $205 \mathrm{~nm}$. The mobile phase was triethylamine $(0.1 \%, \mathrm{pH} 3.0) /$ methanol $=4: 6$ at a flow rate of $0.2 \mathrm{~mL} /$ min and a column temperature of $25{ }^{\circ} \mathrm{C}$. The injection volume was $4 \mu \mathrm{L}$. Samples were centrifuged and then the supernatants were filtered using $0.22-\mu \mathrm{m}$ filter membrane.

\section{Enzyme assay}

L-AAD/L-AAO activity on L-Met was assayed by coupling KMTB formation. One unit of activity was defined as the amount of catalyst that catalyzed the oxidation of $1 \mu \mathrm{mol} \mathrm{L}-\mathrm{Met}$ per minute under the following conditions: $25{ }^{\circ} \mathrm{C}, \mathrm{pH}$ 7.5. The assay mixture contained the substrate solution $(10 \mathrm{mM})$ and the E. coli cells containing overexpressed L-AAD $(5 \mathrm{mg})$. The conversion was determined between 1 and 2.5 min each $30 \mathrm{~s}$. Dehydrogenase activity on KMTB was determined as described previously (Busto et al. 2014). One unit of activity was defined as the amount of catalyst that catalyzes the oxidation of $1 \mu \mathrm{mol}$ NADH per minute by measurement of the absorbance at $340 \mathrm{~nm}$.

\section{Strategy in fed-batch fermentation}

Seed cultures were grown in $500 \mathrm{~mL}$ of LB medium and then inoculated in the 5-L bioreactor fermentation with a 3-L working volume, with an inoculation with $5 \%$ volume of the seed culture. The $\mathrm{pH}$, agitation rate, and aeration rate were adjusted to $7.0,400 \mathrm{rpm}$, and $1.0 \mathrm{vvm}$, respectively. The temperature for cell growth was $37^{\circ} \mathrm{C}$, but after induced with $5 \mathrm{~g} \mathrm{~L}^{-1}$ lactose, the temperature was adjusted to $25^{\circ} \mathrm{C}$ for enzyme expression. When the dissolved oxygen level increased rapidly (demonstrating glycerol in the medium was completely exhausted), the system was supplied with $400 \mathrm{~g} \mathrm{~L}^{-1}$ glucose, $100 \mathrm{~g} \mathrm{~L}^{-1}$ yeast extract, and $25 \mathrm{~g} \mathrm{~L}^{-1}$ tryptone at a rate of $8 \mathrm{~mL} \mathrm{~h}^{-1}$.

\section{Production of R/S-HMTBA from L-Met}

The conversion experiments were carried out a 5-L bioreactor with $1-\mathrm{L}$ working volume. PvL-AAD $\left(20 \mathrm{~g} \mathrm{~L}^{-1}\right.$ wet biomass) was added to a Tris- $\mathrm{HCl}$ buffer $(20 \mathrm{mM}, \mathrm{pH}$ 7.5) containing the L-methionine $\left(100 \mathrm{~g} \mathrm{~L}^{-1}\right)$. The suspension was stirred at $600 \mathrm{rpm}, 25^{\circ} \mathrm{C}$ and aeration rate of $2 \mathrm{vvm}$ for $14 \mathrm{~h}$. After this time, the R-selective wholecell catalyst ( $20 \mathrm{~g} \mathrm{~L}^{-1}$ wet biomass) or the S-selective whole-cell catalyst $\left(20 \mathrm{~g} \mathrm{~L}^{-1}\right.$ wet biomass) and $140 \mathrm{~g} \mathrm{~L}^{-1}$ formate, and $0.4 \mathrm{mM} \mathrm{NAD}^{+}$were added at $30{ }^{\circ} \mathrm{C}$. After a further 9-h incubation, the concentration of KMTB, L-Met, and HMTBA was determined using the HPLC method as described above.

\section{Isolation protocols}

The isolation protocol was the same as the previous report (Busto et al. 2014).

\section{Results}

Designing enzyme cascades for producing (R/S)-HMTBA

The catalysis cascade platform was designed with two main modules (Fig. 1a). The first module is the basic module (BM), in which L-Met is transformed to prochiral KMTB. The other module is the extender module (EM) that is split into two parts, EM1 and EM2, in which KMTB is converted into $(R)$ - and $(S)$-HMTBA, respectively. When BM is coupled with EM1, the complete process is found to produce (R)-HMTBA (Fig. 1b). Similarly, when BM is coupled with EM2, the complete process is found to produce $(S)$-HMTBA. Thus, we could obtain KMTB, $(R)$-HMTBA, and (S)-HMTBA simply with the readily available material L-Met (Fig. 1 ).

The BM starts with the oxidation of L-Met using LAAO or L-AAD to produce KMTB (Fig. 1a). Both L-AAO and L-AAD employ FAD to catalyze the typical deamination of L-Met, yielding the corresponding KMTB and ammonia. The EMs were designed for introducing chiral $-\mathrm{OH}$ groups (Fig. 1a). EM1 was designed for the R-stereoselective reduction of KMTB to $(R)$-HMTBA catalyzed by R-specific dehydrogenases, coupled with NADH recycling by FDH, while EM2 was designed to employ 


\section{$\mathbf{a}$}

Basic Module (BM):<smiles>CSCC[C@H](N)C(=O)O</smiles><smiles>CSCCC(=O)C(=O)O</smiles>

L-Met

KMTB

Extender Module 1(EM1):<smiles>CSCCC(=O)C(=O)O</smiles>

$\stackrel{\text { R-specific dehydrogenase }}{\longrightarrow}$

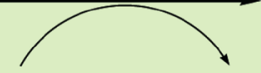<smiles>CSCC[C@@H](O)C(=O)O</smiles>

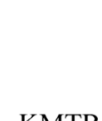
$\mathrm{NADH}$

NAD ${ }^{+}$

KMTB

$\mathrm{CO}_{2}$

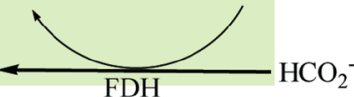

(R)-HMTBA

Extender Module 2(EM2):<smiles>CSCCC(=O)C(=O)O</smiles>

S-specific dehydrogenase
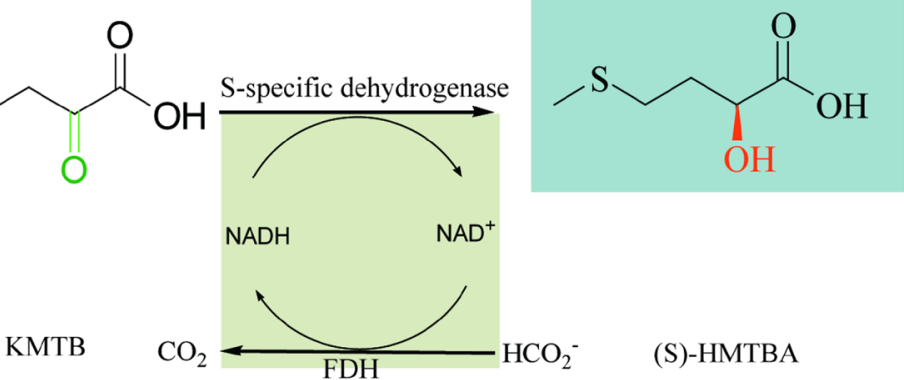

(S)-HMTBA

b

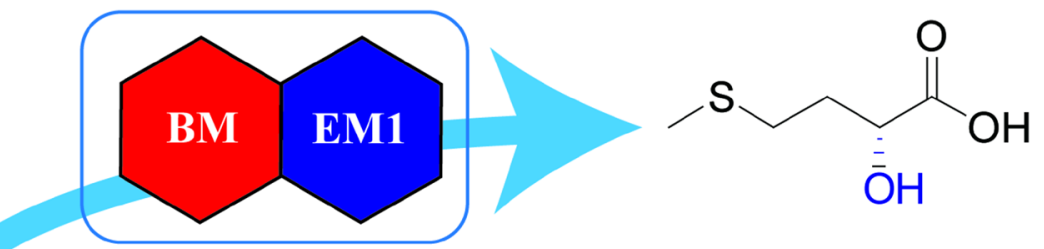<smiles>CSCCC(N)C(=O)O</smiles>

\section{BM}

\section{EM2}<smiles>CSCC[C@H](O)C(=O)O</smiles> 
(See figure on previous page.)

Fig. 1 Modular cascade biocatalysis for synthesis of (R/S)-HMTBA from L-Met. a The modular and combinatorial synthesis of (R/S)-HMTBA by the proposed modular cascade biocatalysis platform. Three general basic enzyme modules: Basic Module: L-amino acid deaminase (L-AAD) or L-amino acid oxidase (L-AAO) for deamination of L-Met to KMTB; Extender Module 1: R-specific dehydrogenase and formate dehydrogenase (FDH) for asymmetric reduction of KMTB to (R)-HMTBA; Extender Module 2: S-specific dehydrogenase and formate dehydrogenase (FDH) for asymmetric reduction of KMTB to (S)-HMTBA. b The artificially designed cascade biocatalysis protocol. Cascade 1: modular assembly for (R)-HMTBA synthesis via cascade BM with EM1. Cascade 2: modular assembly for (S)-HMTBA synthesis via cascade BM with EM2

S-specific dehydrogenases for converting KMTB into $(S)$ HMTBA and FDH for NADH recycling.

The enzymes used in each module were selected on the basis of literature reports on the abilities of specific enzymes and organisms to function in the presence of the required intermediates. To facilitate suitable adjustment of the ratio of different enzymes, each module was cloned into one E. coli strain harboring one plasmid [pET28a $(+)$ ], respectively (Additional file 1: Figure S1). Protein expression was induced with isopropyl- $\beta$-D-lthiogalactopyranoside (IPTG), and an SDS-PAGE analysis confirmed the soluble expression of all the enzymes used (Additional file 1: Figure S2).

\section{Production of KMTB from L-Met}

We initially validated the system design by focusing on building a capable BM (Fig. 1a), which required an efficient enzyme (L-AAD or L-AAO). To this end, the genes encoding two L-AADs from Proteus vulgaris (PvL-AAD) codonoptimized based on the $E$. coli codon preference and $P$. mirabilis (PmirL-AAD) along with seven functionally known L-AAOs were selected from the NCBI database via data mining (Hossain et al. 2014), and expressed in E. coli BL21 (DE3). Next, the activities toward L-Met were tested (Additional file 1: Table S2). No activities were detected in any of the strains overexpressing the L-AAOs. In contrast, $P v_{\mathrm{L}}-\mathrm{AAD}$ and $P$ mir $\mathrm{L}-\mathrm{AAD}$ showed high activities toward L-Met with a specific activity $0.28 \mathrm{U} \mathrm{mg}^{-1}$ and 0.15 $\mathrm{U} \mathrm{mg}^{-1}$ lyophilized cells, respectively. This improved activity is attributed to the fact that L-AADs are membrane bound and transfer electrons of the reduced cofactor to a cytochrome linked to the respiratory chain without hydrogen peroxide production. Therefore, the $P \nu \mathrm{L}-\mathrm{AAD}$ whole-cell catalyst was deemed to be the most suitable for constructing the BM owing to its highest activity.

Tolerance of the high substrate concentration is the key factor to consider when applying enzyme technology on an industrial scale (Groger et al. 2006). Therefore, the transformation was conducted in the presence of $20 \mathrm{~g} \mathrm{~L}^{-1}$ wet biomass with $100 \mathrm{~g} \mathrm{~L}^{-1} \mathrm{~L}$-Met in shake flasks (Fig. 2a). The $P v_{\mathrm{L}}$-AAD whole-cell catalyst produced $77.4 \mathrm{~g} \mathrm{~L}^{-1}$ KMTB in $24 \mathrm{~h}$. Furthermore, the effects of different components and conditions such as $\mathrm{pH}$, temperature, and substrate concentration were optimized (Fig. 2b-d). Under the optimum conditions ( $\mathrm{pH} 7.5,25^{\circ} \mathrm{C}, 100 \mathrm{~g} \mathrm{~L}{ }^{-1} \mathrm{~L}$-Met, and $20 \mathrm{~g} \mathrm{~L}^{-1}$ wet biomass), the titer of KMTB improved to $98.5 \mathrm{~g} \mathrm{~L}^{-1}$ with a conversion rate of $99.2 \%$ (Fig. 2e). The whole-cell catalysis reaction was then performed at $1 \mathrm{~L}$. Under the optimized conditions, a total of $100 \mathrm{~g} \mathrm{~L}^{-1}$ of $\mathrm{L}$-Met was converted after $14 \mathrm{~h}$ of incubation at $25^{\circ} \mathrm{C}$ with an aeration rate of $2 \mathrm{vvm}$, reaching $99.0 \mathrm{~g} \mathrm{~L}^{-1} \mathrm{KMTB}$ (Fig. 2f). The obtained product KMTB was finally identified by mass spectrometry (Additional file 1: Figure S3a) and quantified by HPLC (Additional file 1: Figure S4).

\section{Production of (R)-HMTBA from KMTB}

The substrate specificity of dehydrogenases provides a theoretical basis for choosing dehydrogenase candidates. For one, KMTB and phenylpyruvate (PPA) have a similar structure. However, the KMTB substrate size is smaller than that of the PPA. Therefore, we assumed that dehydrogenases for PPA would also recognize KMTB as a substrate. To construct EM1, highly selective dehydrogenases (ee > 99\%) with an R-stereopreference from Lactobacillus sp. CGMCC9967 (Xu et al. 2016), Lactobacillus paracasei DSM 20008 (Gourinchas et al. 2015), and Pediococcus acidilactici (Mu et al. 2012) were selected and expressed in E. coli BL21 (DE3), respectively. We then tested their activities toward KMTB, showing that the R-specific lactate dehydrogenase (D-LDH) from $P$. acidilactici was the most suitable for the conversion of KMTB to $(R)$-HMTBA with a specific activity of $0.68 \mathrm{U} \mathrm{mg}^{-1}$ lyophilized cells (Additional file 1: Table S3).

Next, we designed an R-selective whole-cell catalyst (Additional file 1: Figure S1b) to construct EM1 using a one-plasmid strategy. The genes that encode the R-specific LDH from $P$. acidilactici and the codon-optimized formate dehydrogenase (FDH) from Candida boidinii were ligated together into plasmid pET28a $(+)$ to obtain pET-28a(+)-FDH-SD-D-LDH. E. coli BL21 was used as the host organism for expression. The transferred strain produced 68.4 $\mathrm{g} \mathrm{L}^{-1}(R)$-HMTBA from $90 \mathrm{~g} \mathrm{~L}^{-1} \mathrm{KMTB}$ in $15 \mathrm{~h}$ (Fig. 3a). The reaction system was then optimized in terms of $\mathrm{pH}$, temperature, and the $\mathrm{NAD}^{+}$addition amount (Fig. 3b-d). Under the optimum conditions $(\mathrm{pH}$ 7.0, $30{ }^{\circ} \mathrm{C}, 0.4 \mathrm{mM} \mathrm{NAD}^{+}, 20 \mathrm{~g} \mathrm{~L}^{-1}$ wet biomass), the titer of $(R)$-HMTBA improved to $88.5 \mathrm{~g} \mathrm{~L}^{-1}$ with a conversion rate of $97.0 \%$ within $15 \mathrm{~h}$ (Fig. 3e). 
a

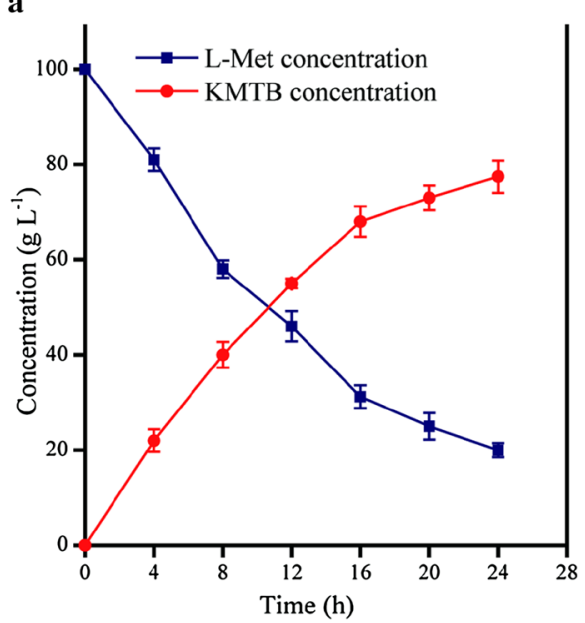

c

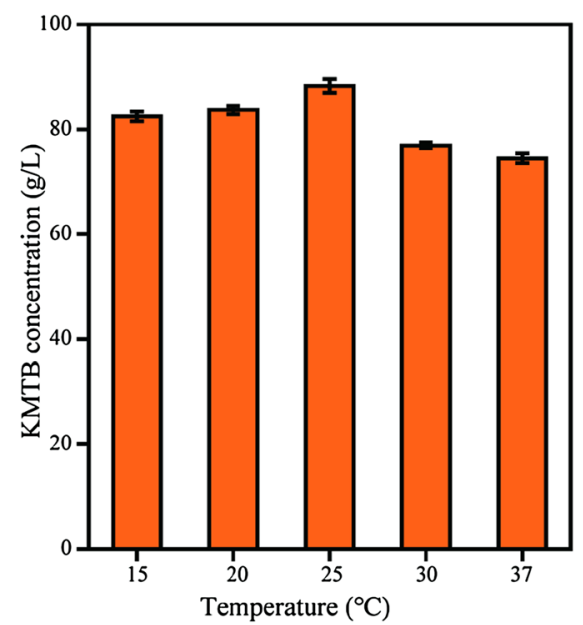

e

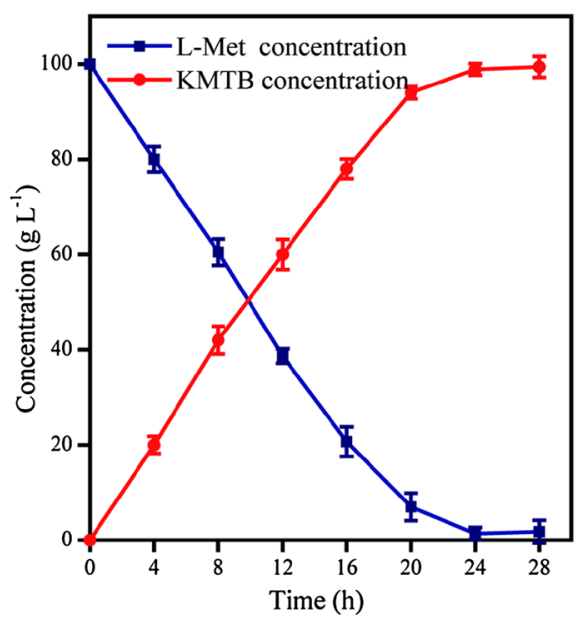

b

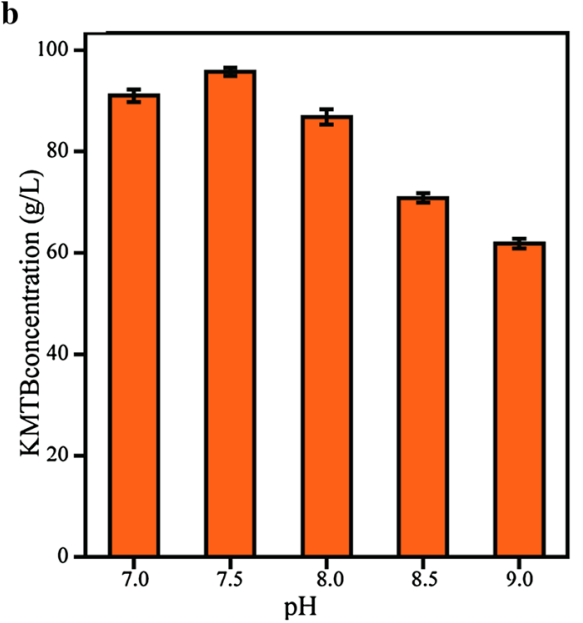

d

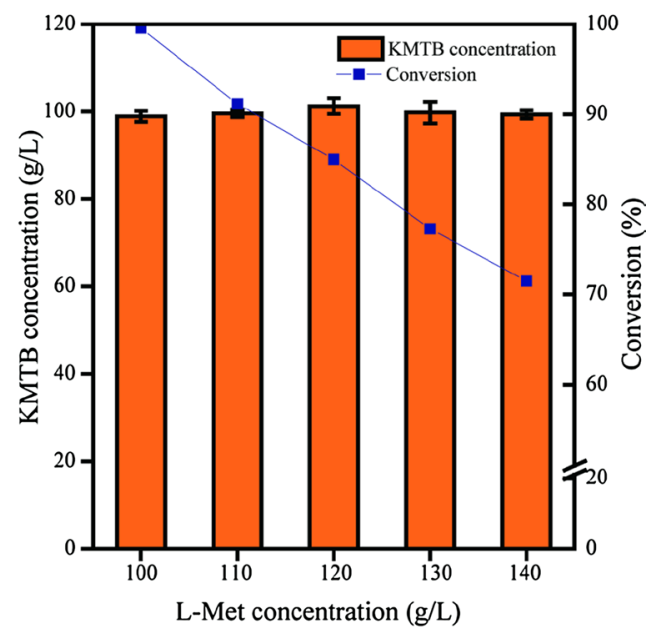

f

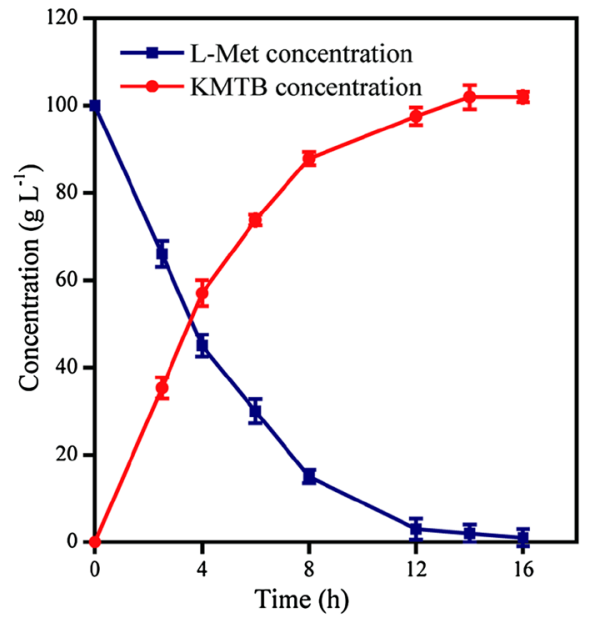

Fig. 2 Optimization of BM. a Time courses of the initial conditions: wet biomass of PVL-AAD E. coli $\left(20 \mathrm{~g} \mathrm{~L}^{-1}\right)$ in Tris-HCl buffer (20 mM, pH 8.0) containing the L-methionine $\left(100 \mathrm{~g} \mathrm{~L}^{-1}\right)$, at $200 \mathrm{rpm}$ and $30^{\circ} \mathrm{C}$. $\mathbf{b}$ Effects of different $\mathrm{pH}$ on KMTB production. $\mathbf{c}$ Effects of different temperatures on KMTB production. $\mathbf{d}$ Effects of substrate loading on KMTB production. e Time course of the optimized conditions: wet biomass of PV-L-AAD E. coli $\left(20 \mathrm{~g} \mathrm{~L}^{-1}\right)$ in Tris-HCl buffer $(20 \mathrm{mM}, \mathrm{pH} 7.5)$ containing the L-methionine $\left(100 \mathrm{~g} \mathrm{~L}^{-1}\right)$, at $200 \mathrm{rpm}$ and $25^{\circ} \mathrm{C}$ at $20-\mathrm{mL}$ scale. f Time course of the optimized conditions at $1-L$ scale 

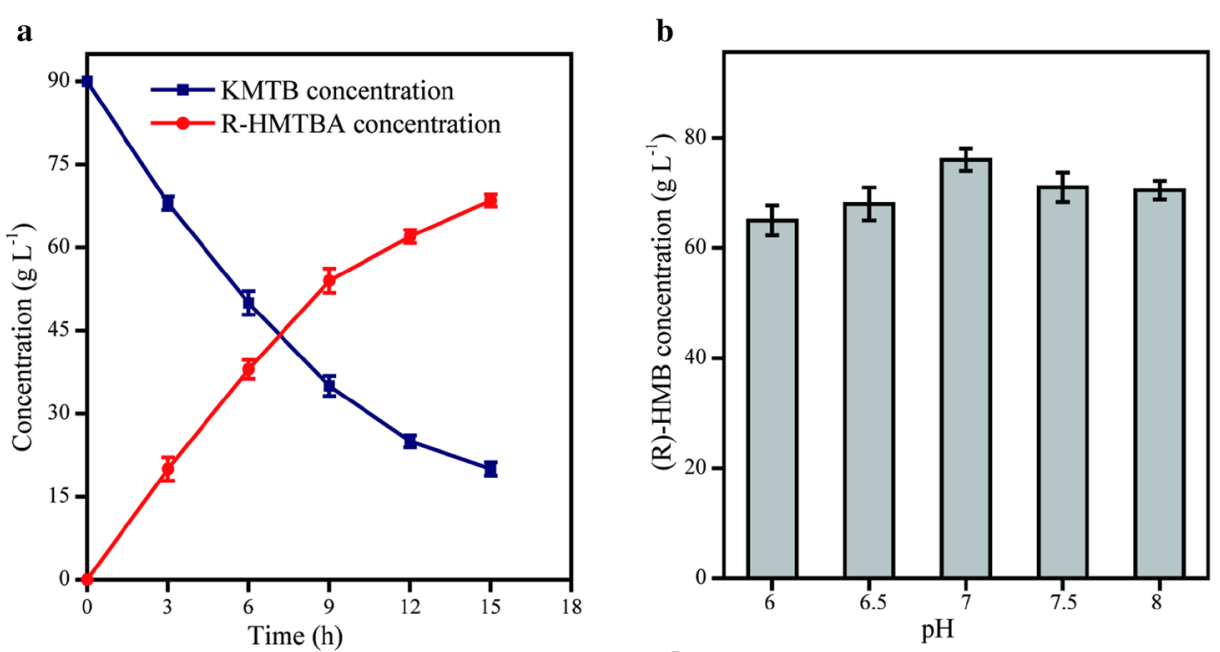

d
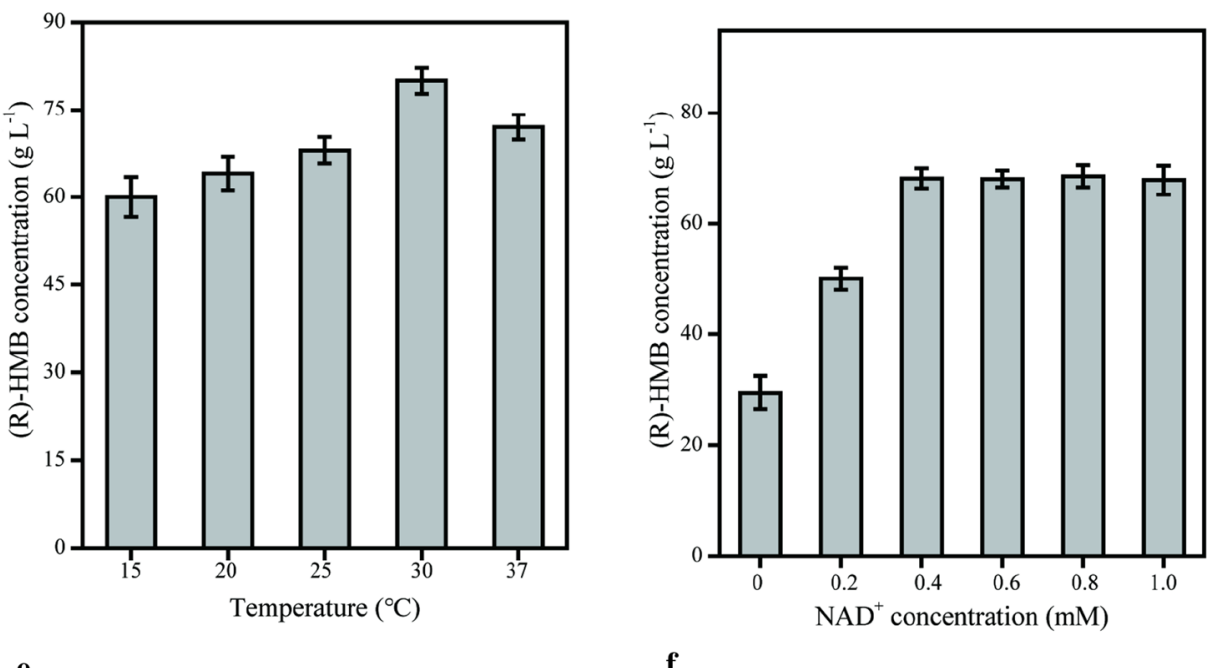

f
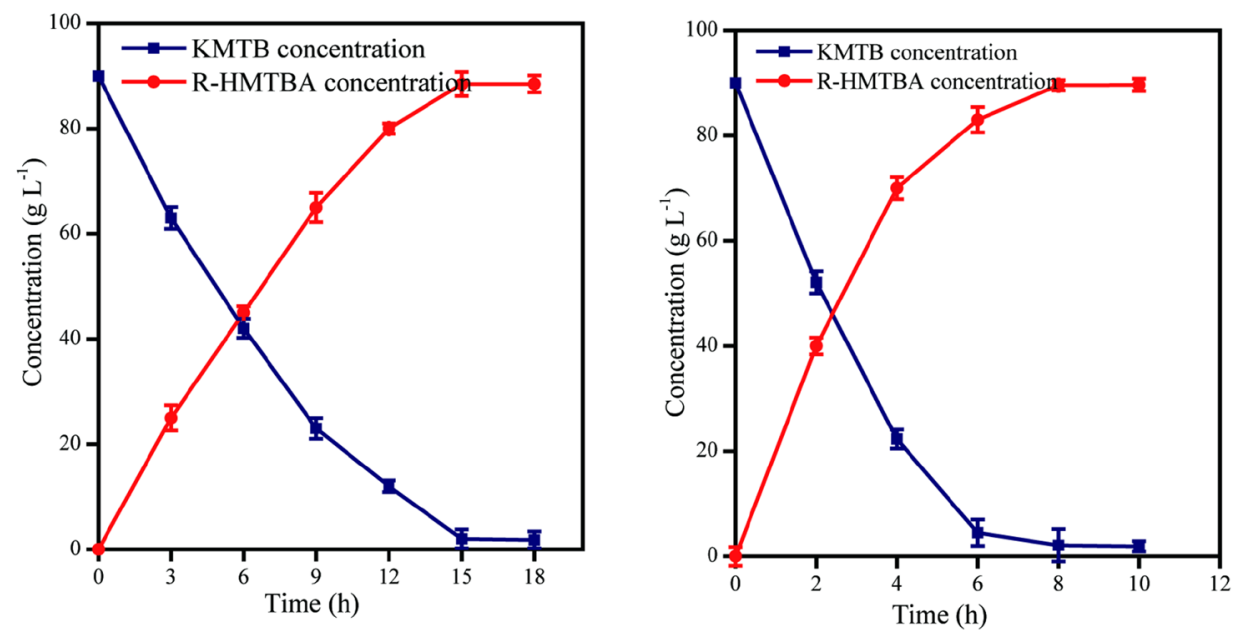

Fig. 3 Optimization of EM1. a Time courses of the initial conditions: wet biomass of R-selective whole-cell catalyst $\left(20 \mathrm{~g} \mathrm{~L}^{-1}\right)$ in $\mathrm{KP}$ buffer $(50 \mathrm{mM}$, $\left.\mathrm{pH} 6.5,1 \mathrm{mM} \mathrm{NAD}^{+}\right)$containing the KMTB $\left(90 \mathrm{~g} \mathrm{~L}^{-1}\right)$ and sodium formate $\left(125 \mathrm{~g} \mathrm{~L}^{-1}\right)$, at $200 \mathrm{rpm}$ and $25^{\circ} \mathrm{C}$. $\mathbf{b}$ Effects of different pH on $(R)$-HMTBA production. $\mathbf{c}$ Effects of different temperatures on (R)-HMTBA production. $\mathbf{d}$ Effects of NAD ${ }^{+}$concentration on (R)-HMTBA production. $\mathbf{e}$ Time course of the optimized conditions: wet biomass of R-selective whole-cell catalyst $\left(20 \mathrm{~g} \mathrm{~L}^{-1}\right)$ in KP buffer $(50 \mathrm{mM}, \mathrm{pH} 7.0,0.4 \mathrm{mM} \mathrm{NAD})$ containing the KMTB $\left(90 \mathrm{~g} \mathrm{~L}^{-1}\right)$ and sodium formate $\left(125 \mathrm{~g} \mathrm{~L}^{-1}\right)$, at $200 \mathrm{rpm}$ and $30^{\circ} \mathrm{C}$ at $20-\mathrm{mL}$ scale. f Time course of the optimized conditions at 1-L scale 
Moreover, the synthetic application of EM1 was demonstrated by biotransformations to produce $(R)$-HMTBA using KMTB at $1 \mathrm{~L}$. Under the optimum conditions, 98.2\% KMTB was converted to ( $R$ )-HMTBA within $8 \mathrm{~h}$ (Fig. 3f). The obtained product ( $R$ )-HMTBA was finally identified by mass spectrometry (Additional file 1: Figure S3b) and quantified by HPLC (Additional file 1: Figure $\mathrm{S} 5 \mathrm{~b})$. The enantiomeric excess of $(R)$-HMTBA (ee $>99 \%)$ was determined by HPLC using a chiral column (Additional file 1: Figure S6b).

\section{Production of (S)-HMTBA from KMTB}

Similarly, to construct EM2, highly selective dehydrogenases (ee $>99 \%$ ) with an S-stereopreference from Lactobacillus confuses DSM20196 (Busto et al. 2014) and Bacillus coagulans (Zheng et al. 2015) were selected and expressed in E. coli BL21 (DE3). As shown in Additional file 1: Table S3, the S-specific lactate dehydrogenase ( $\mathrm{L}-$ $\mathrm{LDH}$ ) from $B$. coagulans was found to be particularly useful owing to its high specific activity toward KMTB of $0.67 \mathrm{U} \mathrm{mg}^{-1}$ lyophilized cells. The analogous S-selective whole-cell catalyst was constructed in the same manner using E. coli BL21 as the host organism using the plasmid pET28a(+), which contained genes encoding the abovementioned L-LDH from $B$. coagulans and the codonoptimized FDH gene from Candida boidinii to obtain pET28a(+)-FDH-SD-L-LDH (Additional file 1: Figure S1c).

This strain produced $67.3 \mathrm{~g} \mathrm{~L}^{-1}(S)$-HMTBA from $90 \mathrm{~g}$ $\mathrm{L}^{-1} \mathrm{KMTB}$ in $15 \mathrm{~h}$ (Fig. 4a). Under the optimum conditions $\left(\mathrm{pH} 7.0,30{ }^{\circ} \mathrm{C}, 0.4 \mathrm{mM} \mathrm{NAD}^{+}, 20 \mathrm{~g} \mathrm{~L}^{-1}\right.$ wet biomass; Fig. $4 \mathrm{~b}-\mathrm{e}$ ), the titer of (S)-HMTBA improved to $87.4 \mathrm{~g} \mathrm{~L}^{-1}$ with a conversion rate of $96.5 \%$ within $15 \mathrm{~h}$.

In addition, the synthetic application of EM2 was demonstrated by biotransformations to produce (S)-HMTBA by KMTB at $1 \mathrm{~L}$. Under the optimum conditions, 96.7\% KMTB was converted to (S)-HMTBA within $8 \mathrm{~h}$ (Fig. 4f). The obtained product (S)-HMTBA was finally identified by mass spectrometry (Additional file 1: Figure S3c) and quantified by HPLC (Additional file 1: Figure S5c). The enantiomeric excess of $(S)$-HMTBA (ee>99\%) was determined by HPLC with a chiral column (Additional file 1: Figure S6c).

\section{One-pot production of $(R / S)$-HMTBA from L-Met}

The BM and EMs were then combined for the production of $(R)$-HMTBA or $(S)$-HMTBA from L-Met in one pot. The cascade for the production of $(R)$-HMTBA or $(S)$ HMTBA was challenging in simultaneous mode owing to the significant differences in the optimal temperatures between the modules $\left(25^{\circ} \mathrm{C}\right.$ for the $\mathrm{BM}$ and $30^{\circ} \mathrm{C}$ for the $\mathrm{EMs})$, resulting in the enzyme incompatibility under the reaction conditions. Therefore, we designed a "two stages in one pot" strategy for the multi-enzyme cascade reaction to produce $(R)$-HMTBA or $(S)$-HMTBA using LMet, respectively (Fig. 5a). In the first stage, the BM was performed to favor $P v_{\mathrm{L}}$-AAD catalysis at $25{ }^{\circ} \mathrm{C}$. In the second stage, EM1 or EM2 was initiated by adding the Ror S-selective whole-cell catalyst, formate, and $\mathrm{NAD}^{+}$at $30^{\circ} \mathrm{C}$.

Next, we tested the one-pot production of $(R)$-HMTBA and $(S)$-HMTBA from L-Met at $1 \mathrm{~L}$, respectively. In the first stage, the $\mathrm{BM}$ was performed at a substrate concentration of $100 \mathrm{~g} \mathrm{~L}^{-1} \mathrm{~L}$-Met at $25^{\circ} \mathrm{C}$, and a conversion rate of $99.6 \%$ was obtained after a reaction time of $14 \mathrm{~h}$ with $20 \mathrm{~g} \mathrm{~L}^{-1} P v_{\mathrm{L}}$-AAD wet biomass (Fig. 5b, c). In the second stage, the reaction temperature was elevated to $30{ }^{\circ} \mathrm{C}$, the optimal temperature for EM1 and EM2. After a further 9-h incubation with $20 \mathrm{~g} \mathrm{~L}^{-1}$ wet biomass for R- or S-selective whole-cell catalyst, $96.9 \%$ and $95.8 \% \mathrm{~L}-$ Met were converted to $(R)$-HMTBA and $(S)$-HMTBA, respectively. Finally, $(R)$-HMTBA and $(S)$-HMTBA were isolated at a $79 \%$ and $77 \%$ yield, respectively, after a simple extraction step.

\section{Discussion}

A two-stage strategy has been widely applied in other multi-enzyme cascades. For example, owing to optimal $\mathrm{pH}$ differences between $\mathrm{P} 450$ monooxygenase and amine dehydrogenase, Yu et al. (2018) applied this strategy to elevate the cyclohexylamine yield up to $92.5 \%$. In addition, Zhang et al. (2017) designed a microenvironment using poly(methacrylic acid) to separate Cytochrome $\mathrm{C}(\mathrm{CytC})$ which has an acidic optimal $\mathrm{pH}$, from alkaline conditions. When operating alongside D-AAO, which is active under alkaline conditions, the cascade throughput showed tenfold enhancement compared to that conducted with unmodified CytC. Liu et al. (2018) also screened a new D-carbamoylase from Arthrobacter crystallopoietes with an optimum $\mathrm{pH}$ of 8.5, which was much more compatible for hydantoinase processes than other reported D- $N$-carbamoylases. As a result, $80 \mathrm{mM}$ L-indolylmethylhydantoin could be fully converted to $\mathrm{D}$-Trp within $12 \mathrm{~h}$ at a $0.5-\mathrm{L}$ scale. Overall, there are three strategies to solve the problem of enzyme incompatibility of the environment: (i) a two-stage strategy from a time perspective, (ii) designing a microenvironment for separating enzymes from the reaction medium from a space perspective, and (iii) screening enzymes with new properties.

In the cascade route designed in the present study, the EMs were used to control the product configurations, respectively. EM1 facilitates the formation of $(R)$ HMTBA via the high stereoselectivity of R-specific LDH, whereas EM2 facilitates the formation of $(S)$-HMTBA via the high stereoselectivity of S-specific LDH. With 


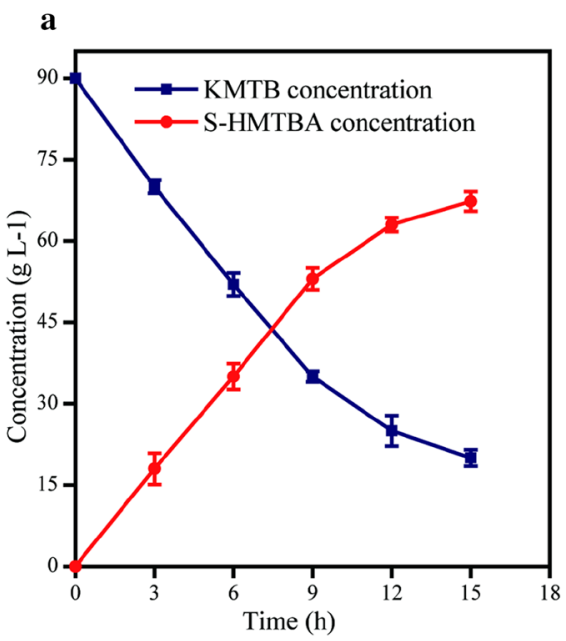

c
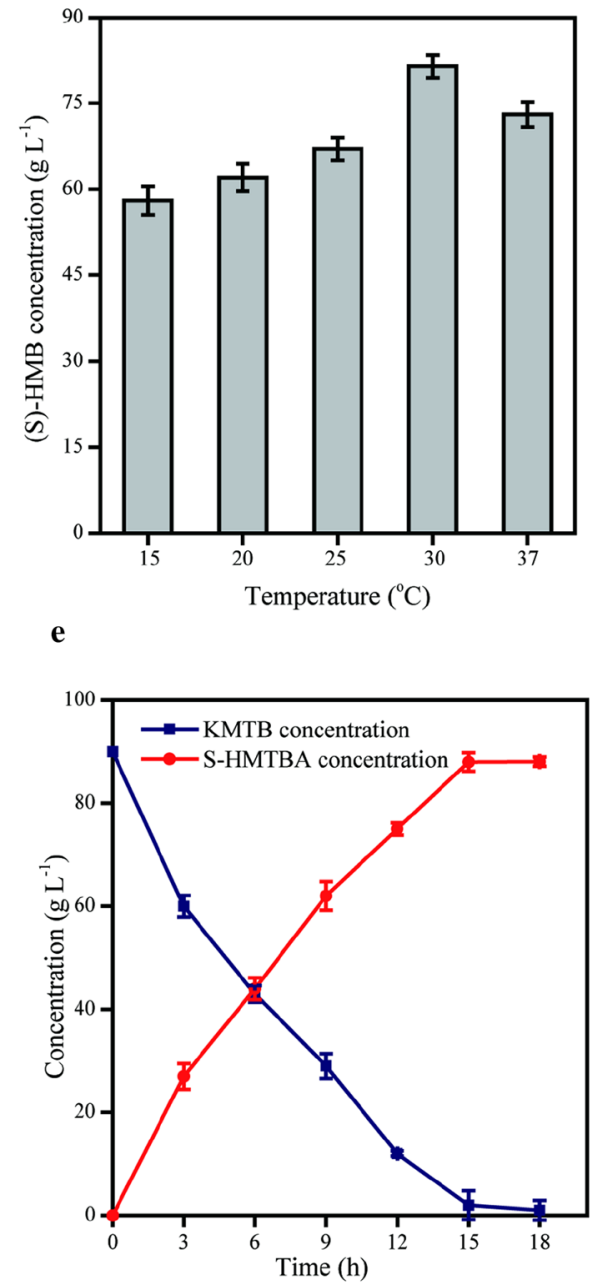

b

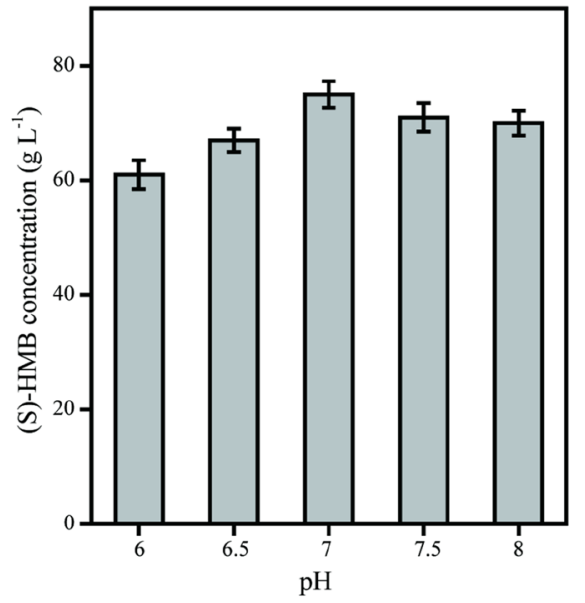

d

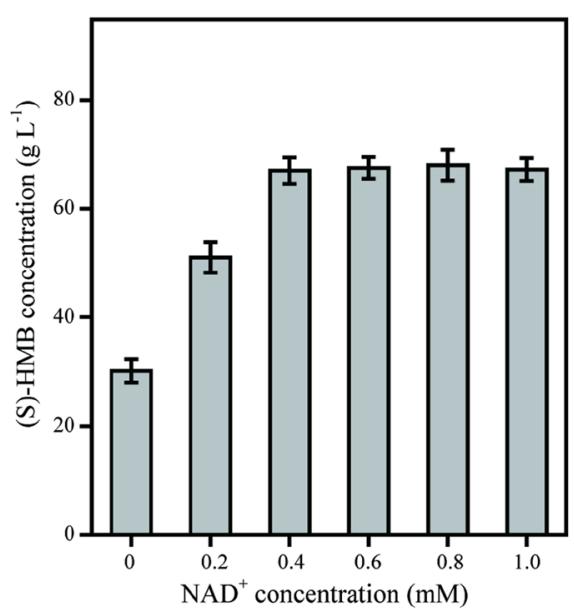

f

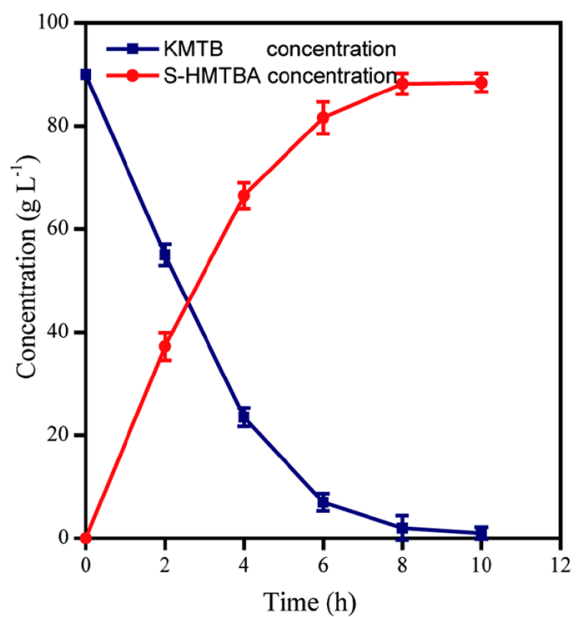

Fig. 4 Optimization of EM2. a Time courses of the initial conditions: wet biomass of S-selective whole-cell catalyst ( $\left.20 \mathrm{~g} \mathrm{~L}^{-1}\right)$ in $\mathrm{KP}^{\text {buffer }}(50 \mathrm{mM}$, $\left.\mathrm{pH} 6.5,1 \mathrm{mM} \mathrm{NAD}^{+}\right)$containing the KMTB $\left(90 \mathrm{~g} \mathrm{~L}^{-1}\right)$ and sodium formate $\left(125 \mathrm{~g} \mathrm{~L}^{-1}\right)$, at $200 \mathrm{rpm}$ and $25^{\circ} \mathrm{C}$. $\mathbf{b}$ Effects of different pH on (S)-HMTBA production. $\mathbf{c}$ Effects of different temperatures on (S)-HMTBA production. $\mathbf{d}$ Effects of NAD ${ }^{+}$concentration on (S)-HMTBA production. e Time course of the optimized conditions: wet biomass of S-selective whole-cell catalyst $\left(20 \mathrm{~g} \mathrm{~L}^{-1}\right)$ in KP buffer $(50 \mathrm{mM}, \mathrm{pH} 7.0,0.4 \mathrm{mM} \mathrm{NAD}$ ) containing the KMTB $\left(90 \mathrm{~g} \mathrm{~L}^{-1}\right)$ and sodium formate $\left(125 \mathrm{~g} \mathrm{~L}^{-1}\right)$, at $200 \mathrm{rpm}$ and $30^{\circ} \mathrm{C}$ at $20-\mathrm{mL}$ scale. $\mathbf{f}$ Time course of the optimized conditions at 1-L scale 
$\mathbf{a}$

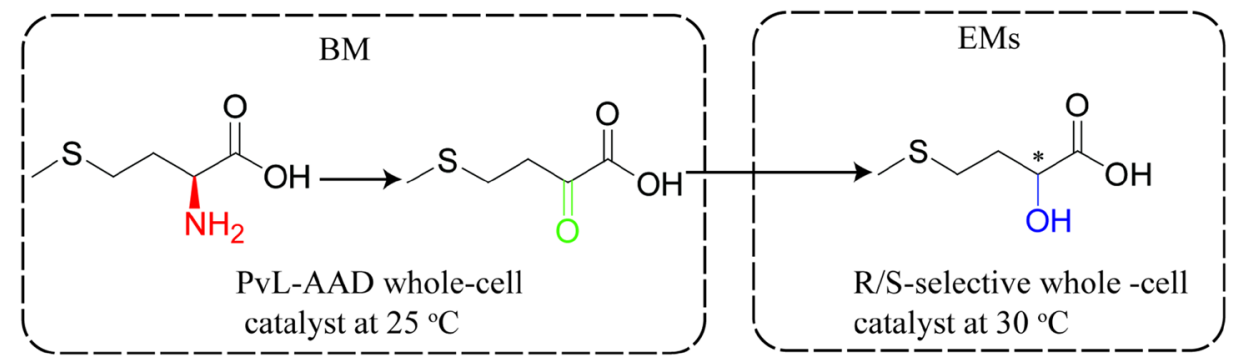

b

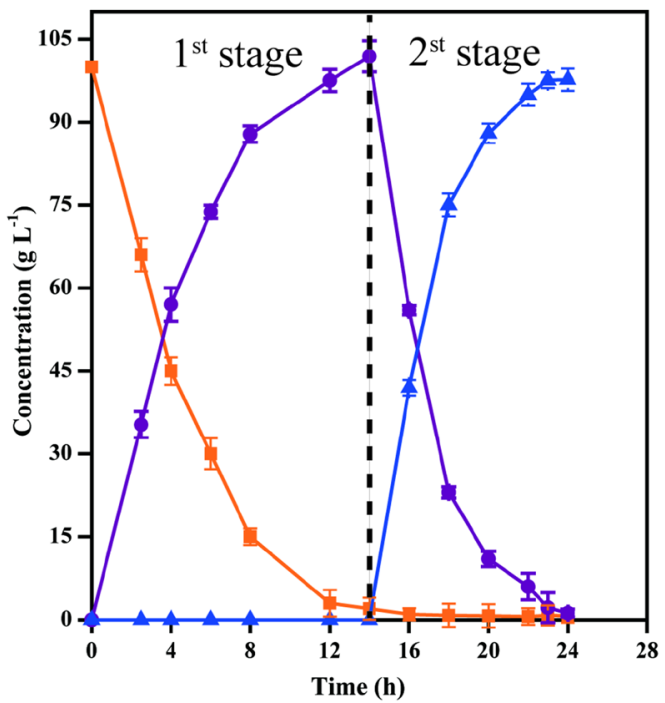

c

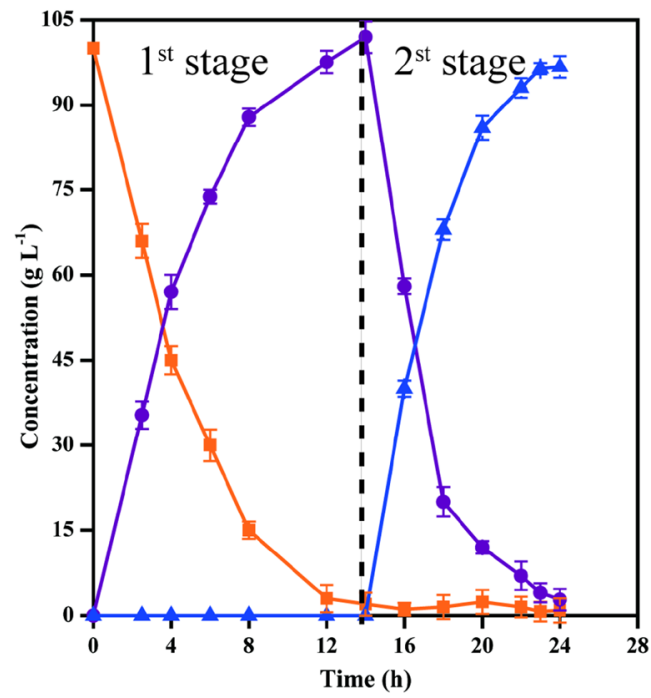

Fig. 5 One-pot production of (R/S)-HMTBA from L-Met. a A "two stages in one-pot" strategy for the multi-enzyme cascade reaction to produce (R)-HMTBA or (S)-HMTBA using L-Met. $\mathbf{b}$ Time courses of the combination of BM and EM1 for producing (R)-HMTBA from L-Met at a 1-L scale using the "two stage in one pot" strategy. c Time courses of the combination of BM and EM2 for producing (S)-HMTBA from L-Met at a 1-L scale using the "two stage in one pot" strategy. For the first stage (0-14 h): a mixture (1 L) of $100 \mathrm{~g} \mathrm{~L}^{-1} \mathrm{~L}-\mathrm{Met}, 20 \mathrm{~g} \mathrm{~L}^{-1} P V \mathrm{~L}-\mathrm{AAD}$ whole-cell catalyst, and $20 \mathrm{mM}$ Tris- $\mathrm{HCl}$ buffer ( $\mathrm{pH} 7.5)$ was incubated at $25^{\circ} \mathrm{C}$. For the second stage (14-23 h): adding $20 \mathrm{~g} \mathrm{~L}^{-1} \mathrm{R} / \mathrm{S}$-selective whole-cell catalyst, $140 \mathrm{~g} \mathrm{~L}^{-1}$ sodium formate, $0.4 \mathrm{mM} \mathrm{NAD}{ }^{+}$. The temperature was adjusted from 25 to $30^{\circ} \mathrm{C}$ and $\mathrm{pH}$ was controlled at 7.0 by $4 \mathrm{M} \mathrm{HCl}$. Symbols: (orange square) L-Met, (purple circle) KMTB (intermediate), and (blue triangle) (R/S)-HMTBA

this level of control, optically pure (R)-HMTBA and $(S)$-HMTBA were finally obtained, respectively. From an organic synthesis perspective, to achieve control of product configurations, use of the whole cascade is advantageous over the majority of other enzymatic (e.g., asymmetric reduction, HMTBN as a substrate, kinetic resolution) and chemical processes. Asymmetric reduction uses keto acids (Gao et al. 2017; Parmeggiani et al. 2016) as substrates; however, KMTB is not an available substrate and is much more expensive than the corresponding L-Met. Nitrilase- or nitrile hydratase-mediated enzymatic processes use HMTBN as a substrate and show low stereoselectivity (Rey et al. 2004); the yield of a kinetic resolution by enzymatic catalysts is limited to only $50 \%$ because only half the configuration is converted (Xue et al. 2013). In the related chemical diazotization process, the product configurations are the same as natural L-amino acids and cannot easily be inversed (Busto et al. 2014).

In summary, we have developed an elegant biocatalytic process that nicely exploits the power of cascades, with several advantages. First, the process is clean because of the use of molecular oxygen as an oxidant and formate as a reducing agent, while only water and $\mathrm{CO}_{2}$ are generated as by-products. Second, this biocatalytic cascade shows industrial application potential with large-scale $(1 \mathrm{~L})$ preparation confirmed. Furthermore, this elegant route will enable the preparation of other valuable enantiopure 
chiral 2-hydroxy acids. The substrate scopes of $P \nu_{\mathrm{L}}-\mathrm{AAD}$ and LDHs are currently under investigation to further expand the diversity of this designed biocascade route.

\section{Conclusions}

We developed an artificially designed biocatalytic cascade that comprises a BM and two different EMs (EM1 and EM2) for the asymmetric synthesis of HMTBA from L-Met in a modular assembly manner. This biocatalytic cascade uses a two-stage strategy to avoid incompatibility of the enzyme environment for the different modules due to their different optimal reaction temperatures $\left(25^{\circ} \mathrm{C}\right.$ for the $\mathrm{BM}$ and $30{ }^{\circ} \mathrm{C}$ for the EMs). EM1 and EM2 facilitate the control of product configurations. Thus, this biocatalytic process exhibits great potential for the large-scale production of enantiopure (R)- or $(S)$-HMTBA.

\section{Additional file}

Additional file 1. Addtional figures and tables.

\begin{abstract}
Abbreviations
L-Met: L-methionine; KMTB: a-keto- $\gamma$-methylthiobutyric acid; HMTBA: 2-hydroxy-4-(methylthio)butanoic acid; HMTBN: 2-hydroxy-4-(methylthio) butanenitrile; HMTBAm: 2-hydroxy-4-(methylthio)butanamide; L-AAO: L-amino acid oxidase; L-AAD: L-amino acid deaminase; BM: basic module; EM: extender module; CGMCC: China General Microbiological Culture Collection Center; LDH: lactate dehydrogenase; PPA: phenylpyruvate; FDH: formate dehydrogenase; FDH: formate dehydrogenase; D-LDH: R-specific lactate dehydrogenase: L-LDH: S-specific lactate dehydrogenase.
\end{abstract}

\section{Authors' contributions}

CZ and LML conceived the study. CZ made contributions to the design of the experiments, the acquisition of data, the analysis and interpretation of data and contributed to the manuscript writing. WS JL XLC and LML conceived and organized the study and helped to draft the manuscript, and have revised the manuscript. All authors read and approved the final manuscript.

\section{Author details}

1 State Key Laboratory of Food Science and Technology, Jiangnan University, 1800 Lihu Road, Wuxi 214122, China. ${ }^{2}$ Key Laboratory of Industrial Biotechnology, Ministry of Education, Jiangnan University, Wuxi 214122, China. ${ }^{3}$ National Engineering Laboratory for Cereal Fermentation Technology, Jiangnan University, Wuxi 214122, China.

\section{Acknowledgements}

Not applicable.

\section{Competing interests}

The authors declare that they have no competing interests.

\section{Availability of data and materials}

All data generated or analyzed during this study are included in this article.

\section{Consent for publication}

All authors approved the consent for publishing the manuscript to bioresources and bioprocessing.

Ethics approval and consent to participate Not applicable.

\section{Funding}

This work was funded by the National First-class Discipline Program of Light Industry Technology and Engineering (LITE2018-08), Jiangsu Province"333 High-level Talents Cultivating Project" (BRA2016365), and the Key Technologies R \& D Program of Jiangsu Province (BE2018623, BE2015307).

\section{Publisher's Note}

Springer Nature remains neutral with regard to jurisdictional claims in published maps and institutional affiliations.

Received: 4 January 2019 Accepted: 11 February 2019

Published online: 20 February 2019

\section{References}

Busto E, Richter N, Grischek B, Kroutil W (2014) Biocontrolled formal inversion or retention of L-alpha-amino acids to enantiopure (R)- or (S)-hydroxyacids. Chem Eur J 20:11225-11228

Grund AD, Millis JR, Blackburn TF, Burlingame RP, Fernando S-R (2000) Enzymatic conversion of a-hydroxynitriles to the corresponding a-hydroxyamides, acids or acid salts patent EP0972066 19 Jan 2000

Dibner JJ, Buttin P (2002) Use of organic acids as a model to study the impact of gut microflora on nutrition and metabolism. J Appl Poultry Res $11: 453-463$

Gao XZ, Zhang Z, Zhang Y, Li Y, Zhu H, Wang S, Li C (2017) A newly determined member of the meso-diaminopimelate dehydrogenase family with a broad substrate spectrum. Appl Environ Microb 83:e00476-17

Gourinchas G, Busto E, Killinger M, Richter N, Wiltschi B, Kroutil W (2015) A synthetic biology approach for the transformation of L-alpha-amino acids to the corresponding enantiopure (R)- or (S)-al pha-hydroxy acids. Chem Commun 51:2828-2831

Groger H, Chamouleau F, Orologas N, Rollmann C, Drauz K, Hummel W, Weckbecker A, May O (2006) Enantioselective reduction of ketones with "designer cells" at high substrate concentrations: highly efficient access to functionalized optically active alcohols". Angew Chem Int Edit 45:5677-5681

Hagiya K (2008) Process for producing 2-hydroxy-4-(methylthio)butyrate compounds and intermediates thereof patent WO2008010609 24 Jan 2008

Hossain GS, Li JH, Shin HD, Du GC, Wang M, Liu L, Chen J (2014) One-step biosynthesis of alpha-keto-gamma-methylthiobutyric acid from L-methionine by an Escherichia coli whole-cell biocatalyst expressing an engineered L-amino acid deaminase from Proteus vulgaris. PLOS ONE 9:e114291

Jin LQ, Guo DJ, Li ZT, Liu ZQ, Zheng YG (2016) Immobilization of nitrilase on bioinspired silica for efficient synthesis of 2-hydroxy-4-(methylthio) butanoic acid from 2-hydroxy-4-(methylthio)butanenitrile. J Ind Microbiol Biotechnol 43:585-593

Koji H, Hiroyuki A (2009) Method for producing 2-hydroxy-4-(methylthio) butyric acid patent US2009053781 26 Feb 2009

Liu YF, Xu GC, Han RZ, Dong JJ, Ni Y (2018) Identification of D-carbamoylase for biocatalytic cascade synthesis of D-tryptophan featuring high enantioselectivity. Bioresour Technol 249:720-728

Luo ZW, Lee SY (2017) Biotransformation of $p$-xylene into terephthalic acid by engineered Escherichia coli. Nat Commun 8:15689

Martin-Venegas R, Brufau MT, Guerrero-Zamora AM, Mercier Y, Geraert PA, Ferrer R (2013) The methionine precursor DL-2-hydroxy-(4-methylthio) butanoic acid protects intestinal epithelial barrier function. Food Chem 141:1702-1709

Masud T, Young VR, Chapman T, Maroni BJ (1994) Adaptive responses to verylow protein diets-the first comparison of ketoacids to essential aminoacids. Kidney Int 45:1182-1192

Matsuoka K (1993) Process for producing 2-hydroxy-4-methylthiobutanoic acid patent WO9323372 25 Nov 1993

Molla G, Melis R, Pollegioni L (2017) Breaking the mirror: L-amino acid deaminase, a novel stereoselective biocatalyst. Biotechnol Adv 35:657-668

Mu WM, Yu SH, Jiang B, Li XF (2012) Characterization of D-lactate dehydrogenase from Pediococcus acidilactici that converts phenylpyruvic acid into phenyllactic acid. Biotechnol Lett 34:907-911 
Olivier F-B, Philippe M, Christophe D, Dominique H (2001) Industrial scale process for the preparation of 2-hydroxy-4-methylbutyric acid using a nitrilase patent US6180359 30 Jan 2001

Parmeggiani F, Ahmed ST, Thompson MP, Weise NJ, Galman JL, Gahloth D, Dunstan MS, Leys D, Turner NJ (2016) Single-biocatalyst synthesis of enantiopure D-arylalanines exploiting an engineered D-amino acid dehydrogenase. Adv Synth Catal 358:3298-3306

Rey P, Rossi JC, Taillades J, Gros G, Nore O (2004) Hydrolysis of nitriles using an immobilized nitrilase: applications to the synthesis of methionine hydroxy analogue derivatives. J Agric Food Chem 52:8155-8162

Ruest DA, Takano M, Wolf LR (1985) Liquid 2-hydroxy-methylthiobutyric acid and process for the preparation thereof patent EP0142488 26 June 1985

Song Y, Li JH, Shin HD, Liu L, Du GC, Chen J (2016) Biotechnological production of alpha-keto acids: current status and perspectives. Bioresour Technol 219:716-724

Song W, Wang JH, Wu J, Liu J, Chen XL, Liu LM (2018) Asymmetric assembly of high-value alpha-functionalized organic acids using a biocatalytic chiralgroup-resetting process. Nat Commun 9:3818

Tang X, Yang YL, Shi YH, Le GW (2011) Comparative in vivo antioxidant capacity of DL-2-hydroxy-4- methylthiobutanoic acid (HMTBA) and DL-methionine in male mice fed a high-fat diet. J Sci Food Agr 91:2166-2172

Tsuyoshi M, Masahiro K (2006) Method for producing 2-hydroxy-4-methylthiobutanoic acid patent JP2006069992 16 Mar 2006

Xu GC, Zhang LL, Ni Y (2016) Enzymatic preparation of D-phenyllactic acid at high space-time yield with a novel phenylpyruvate reductase identified from Lactobacillus sp. CGMCC 9967. J Biotechnol 222:29-37
Xue YP, Zheng YG, Zhang YQ, Sun JL, Liu ZQ, Shen YC (2013) One-pot, singlestep deracemization of 2-hydroxyacids by tandem biocatalytic oxidation and reduction. Chem Commun 49:10706-10708

Xue YP, Zeng $H$, Jin XL, Liu ZQ, Zheng YG (2016) Enantioselective cascade biocatalysis for deracemization of 2-hydroxy acids using a three-enzyme system. Microb Cell Fact 15:162

Xue YP, Cao CH, Zheng YG (2018) Enzymatic asymmetric synthesis of chiral amino acids. Chem Soc Rev 47:1516-1561

Yao PY, Cui YF, Yu SS, Du YC, Feng JH, Wu QQ, Zhu DM (2016) Efficient biosynthesis of $(R)$ - or (S)-2- hydroxybutyrate from L-threonine through a synthetic biology approach. Adv Synth Catal 358:2923-2928

Yu HL, Li T, Chen FF, Luo XJ, Li AT, Yang C, Zheng GW, Xu JH (2018) Bioamination of alkane with ammonium by an artificially designed multienzyme cascade. Metab Eng 47:184-189

Zhang YF, Wang Q, Hess H (2017) Increasing enzyme cascade throughput by $\mathrm{pH}$-engineering the microenvironment of individual enzymes. ACS Catal 7:2047-2051

Zheng ZJ, Zhao MY, Zang Y, Zhou Y, Ouyang J (2015) Production of optically pure L-phenyllactic acid by using engineered Escherichia coli coexpressing L-lactate dehydrogenase and formate dehydrogenase. J Biotechnol 207:47-51

\section{Submit your manuscript to a SpringerOpen ${ }^{\odot}$ journal and benefit from:}

- Convenient online submission

- Rigorous peer review

- Open access: articles freely available online

- High visibility within the field

- Retaining the copyright to your article

Submit your next manuscript at $\boldsymbol{\nabla}$ springeropen.com 